DOI: $10.22616 /$ REEP.2020.002

\title{
Formation of Professional Competence of the Future Computer Engineer in a Technical University
}

\author{
Nadezhda Almazova ${ }^{1}$ Dr.sc.; Anna Rubtsova ${ }^{2}$ Dr.sc. \\ Maria Odinokaya ${ }^{3} \mathrm{PhD}$; Maya Bernavskaya ${ }^{4} \mathrm{PhD}$ \\ Peter the Great St. Petersburg Polytechnic University, Russia \\ almazovanadia1@yandex.ru1'; annarub2011@yandex.ru²; World.Maria@hotmail.com³ \\ bernavskaya@mail.ru ${ }^{4}$
}

\begin{abstract}
The paper considers the relevance of the formation of professional competence of future specialists associated with the features of engineering activities of computer profile. The aim of the study is to analyse of psychological and pedagogical literature and current educational standards, an attempt is made to understand the expected results of training first- and second-year students of engineering study programs, taking into account current trends in the engineering industry. The article attempts to clarify the concepts "professional competence of an engineer". The study demonstrates positive dynamics of development in most indicators. There is a qualitative growth in the following indicators: projective and prognostic skills; organizational skills; information skills; analytical skills and efficiency of knowledge; and the greatest development is obtained during training in the Bachelor's degree. The general conclusion is that the Russian technical university lays a positive dynamic in the development of professional competence. A technical university provides ample opportunities to encourage the development of professional and personal potential student, creating conditions for professional development, reflected in the successful implementation of professional functions, as well as contributing to excellence, by bringing the personal contribution of the engineer, which enriches the experience of the profession in the engineering field.
\end{abstract}

Keywords: professional competence, computer engineer, technical university.

\section{Introduction}

At the present stage of development of the engineering education there are changes, in particular, in engineering personnel of a computer profile caused by multi-layered economy of Russia and a variety of the professional and educational interests of the population forming market demand for staffing of hi-tech productions. The training of highly qualified engineering personnel largely determines the success of solving the leading task of social development on the formation of the innovative economy of the country. An engineer in modern conditions should be responsible for quality of the rendered services before society, before authorized bodies (Odinokaya et al., 2019b). The engineer needs to have a value attitude to his professional activity, in particular, to the project being developed, as well as to be aware of the measure of responsibility for the decisions made. The engineer should be focused on the performance of duties in a subject area of activity, and have the ability to flexibly change professional functions, using professionally significant information technology, that is, to be professionally competent.

Engineering activity is multifunctional and poly-subject and is based on the laws, methods of transformative activity corresponding to the perspective conditions of social development, manifested in the totality of competencies and competencies of invariant and subject-transformative nature. At the present stage of development of society engineering activity is directed on development, production, introduction of the most difficult products and designs (Odinokaya et al., 2019a).

A modern engineer, as a representative of one of the most numerous and significant social and professional groups that determine the further progress of mankind, needs to have creative potential, the ability to self-development and self-improvement, the creation and transfer of values of a healthy lifestyle, which, in turn, is fixed in the Federal State Standards of Higher Education in the form of general cultural, general professional, professional competencies, as a response to the designated social request. At the moment, the development of basic professional educational programs should be carried out with the participation of enterprises-employers of the region, taking into account the requirements reflected in the professional standards. 
The development of technology leads to a change in the paradigm of production-some professions disappear, new ones become familiar, which previously appeared only in science fiction literature, and modern requirements for the third radically change the approach to training. Modern businesses face a situation of improving their technology and produce new products, depending on use of scientific method in manufacture, change of consumption habits and rise of manufacture multiplicity including change of customer options. This situation has increased qualified person demand, which is an important factor in fulfilment of this need. The graduated engineers experience difficulty in the work place with the given education during the period of upper education when they first begin any work. Additionally, in a period of time they require help from other workers and believe that they need additional education in order to work in the better position they desired (Ertug, Goksel, 2019). The gap between the demands of employers and the real competence of graduates is large. Actualization of the problem of formation of professional competence of future engineers is one of the key markers of modern professional education.

\section{Theoretical background}

The analysis of the studies devoted to the question of formation of professional competence of the future engineer in educational space is consecrated in works as domestic (Almazova, Baranova, Khalyapina, 2019; Rubtsova, 2019) and western authors (Goft, Terpenny, 2012; Drabik, Gil, Nowacka, 2013; Briede, Pēks, 2014; McKinley, 2014; Knutson, 2015; Azmi, Kamin, Noordin, 2018; Lasauskiene, Bagdonaviciute, 2018; Sinkus, 2019), represents the actual and demanding further research direction. The researchers emphasize that one of the key roles in the successful development of society is occupied by engineering personnel.

Under the professional competence of an engineer is understood the ability and willingness to reflexively successfully carry out multi-functional, multi-subject, complex engineering and technical activities by solving professional problems that go beyond the main type of professional activity, having scientific and technical knowledge, skills, skills of professional activity; on the basis of the formed abilities aspiring to independence, self-restoration, self-actualization, self-improvement, responsibility, creativity, professional cooperation; promptly adapting in a rapidly changing environment; endowed with personal qualities and having a sense of responsibility for the results of professional activity and awareness of socio-economic and environmental consequences. The professional competence of the engineer is understood as the ability and culture to carry out qualified professional activities in the field of engineering. In the educational process of a technical university, a generalized model of a certain profile of professional activity of a specialist is implemented, in particular, a computer profile, according to which a student needs to gain knowledge, master specific activities, develop and develop professionally important qualities. Through competence, the generalization of educational information about the object, means of activity, the subject in the manner of actions that ensure the quality of certain educational work is carried out (Almazova, Baranova, Khalyapina, 2019).

As the basic components of professional competencies, it is necessary to allocate knowledge, designed in a system of professional concepts; experience of professional activity; focus on transversal competences (comprising critical thinking, collaboration, creativity, innovative thinking and life-long learning competences), business-related competences (comprising business management and personal management competences) and foreign language-related competences (comprising linguistic, interpersonal, strategic and pragmatic competences) (Sinkus, 2019). Thus, as part of the professional competencies in the direction of training "Software engineering", the following basic components can be conditionally distinguished: the ability to formalize in their subject area, taking into account the limitations of the research methods used; ready to use methods and tools the study of objects of professional activity; willingness to justify design decisions, to carry out the formulation and execution of experiments to validate them for correctness and efficiency; ability to prepare presentations, to issue scientific and technical reports on the results of performed work, to publish research results in the form of articles and presentations at scientific conferences; skills of modelling, analysis and use of formal methods of software design; ability to assess the temporal and capacitive complexity of the software.

Professional competence is formed and implemented in the course of all types of practices through the actualization of the following engineering skills: projective and prognostic skills; students emphasize the need to develop projective skills as a primary indicator of professional maturity of young 
professionals; organizational skills; these skills are indicators of intrapersonal potential for self-healing, including the development of communication skills; information skills; the development of these skills contributes to the saturation of modern technical university electronic information resources; analytical skills and efficiency of knowledge; these skills are associated with scientific and theoretical activities.

Special attention should be paid to the aspects of general cultural development of Bachelors of technical university: personal colouring of knowledge, that is, enthusiasm for their professional sphere of activity, a measure of responsibility in making professional decisions, communication, manifested in the disposition to people, goodwill, sociability; perceptivity (professional observation, professional intuition, the presence and manifestation of sensory indicators, assertiveness; dynamism of the personality, arising in emotional stability, ability to self-regulation, liability, culture of professional communication (professional tact).

The purpose of this study is to identify the importance of professional competence for their productive professional activities. The objectives of the study are to consider and compare the process of development of analytical, predictive, projective, reflective, organizational, information and developmental skills of students of the computer profile of the Federal state Autonomous educational institution of higher education "Peter the Great St. Petersburg Polytechnic University" as a basis for the formation of professional competence.

\section{Methodology}

In connection with the relevance of the topic, the author conducted a survey on the basis of the Federal State Autonomous Educational Institution of Higher Education "Peter the Great St. Petersburg Polytechnic University". The aim of the pedagogical experiment was to identify the self-assessment of the current state of professional competence of future computer engineers, competence of Bachelors (future engineers of computer profile) $1^{\text {st }}$ and $2^{\text {nd }}$ year students of computer profile. Bachelor's degree is the main form of professional training in Russia. Its introduction, instead of the traditional "specialty" was a step of the Russian labour market towards the international market. Russian students receive this degree as part of a three- or four-year program. These are officially regulated terms defined by law (Federalnij zakon..., 2019).

The choice of the participation of $1^{\text {st }}$ and $2^{\text {nd }}$ year students is justified by the fact that during these years of study at the educational institution they are consciously preparing for the design of a professional life path, the process of formation of the essential qualities affecting the efficiency of the activity and the success of its development takes place. There is also an opportunity to realize the difficulties that students face in the process of forming professional competence and make efforts to eliminate. It is difficult to implement it during the last courses of study, since students are already completing their studies.

The survey was attended by 45 students (on the example of the direction of training "Software engineering"), who graduated from the first and second year. Students were asked to answer 11 questions of a pre-developed questionnaire.

1. Give your opinion on the idea of your professional activity.

2. Evaluate your professional skills in the sphere of engineering.

3. Express your opinion on your scientific and technical skills of professional activities implementation, characterized by awareness in the engineering field.

4. Express your opinion about your communication and analytical potential.

5. Express your opinion about your professional culture and ethics, manifestation of your value attitude, in particular, awareness of responsibility for your professional activities.

6. Give your opinion on your theoretical background.

7. Express your opinion about your practical training.

8. Express your opinion about your production discipline in order to prevent failure, the potential for self-education and self-establishment, compliance with environmental safety of the organization of working team, compliance with industry requirements for product quality.

9. Express your opinion about your adaptation to professional working conditions.

10. Give your opinion on your cloud technology proficiency.

11. Evaluate your personal progress. 
Questions 1 to 5 related to the identification of the current state of knowledge and skills in the field of professional activity. Questions 6 to 8 are aimed at identifying shortcomings in the professional training of students. Questions 9 to 10 are aimed at identifying the difficulties that the student had to face when solving problems in the field of professional activity. Question 11 was aimed at assessing personal growth.

The analysis of the survey results of 1 st and 2nd year students of a direction "Software engineering" Federal State Autonomous Educational Institution of Higher Professional Education "Peter the Great St. Petersburg Polytechnic University", as well as analysis of expert evaluation of the teacher for whom the students were attached to the practice has allowed to reveal the real state of training of Bachelorengineers of computer profile. The analysis of questionnaires showed that at the time of carrying out pedagogical experiment it is necessary to consider features of future professional activity of students (in the future - engineers).

The object of this study was the professional competence of students of technical university, the subjectthe process of formation of elements of professional competence of students (future engineers). The methodological basis of the study was a comparative analysis of questionnaires of $1^{\text {st }}$ and $2^{\text {nd }}$ year students of computer profile. The study had a prolonged character: in 2017, students of the direction "Software engineering" filled out a questionnaire, in 2018, as 2nd year students, they re-answered a similar questionnaire.

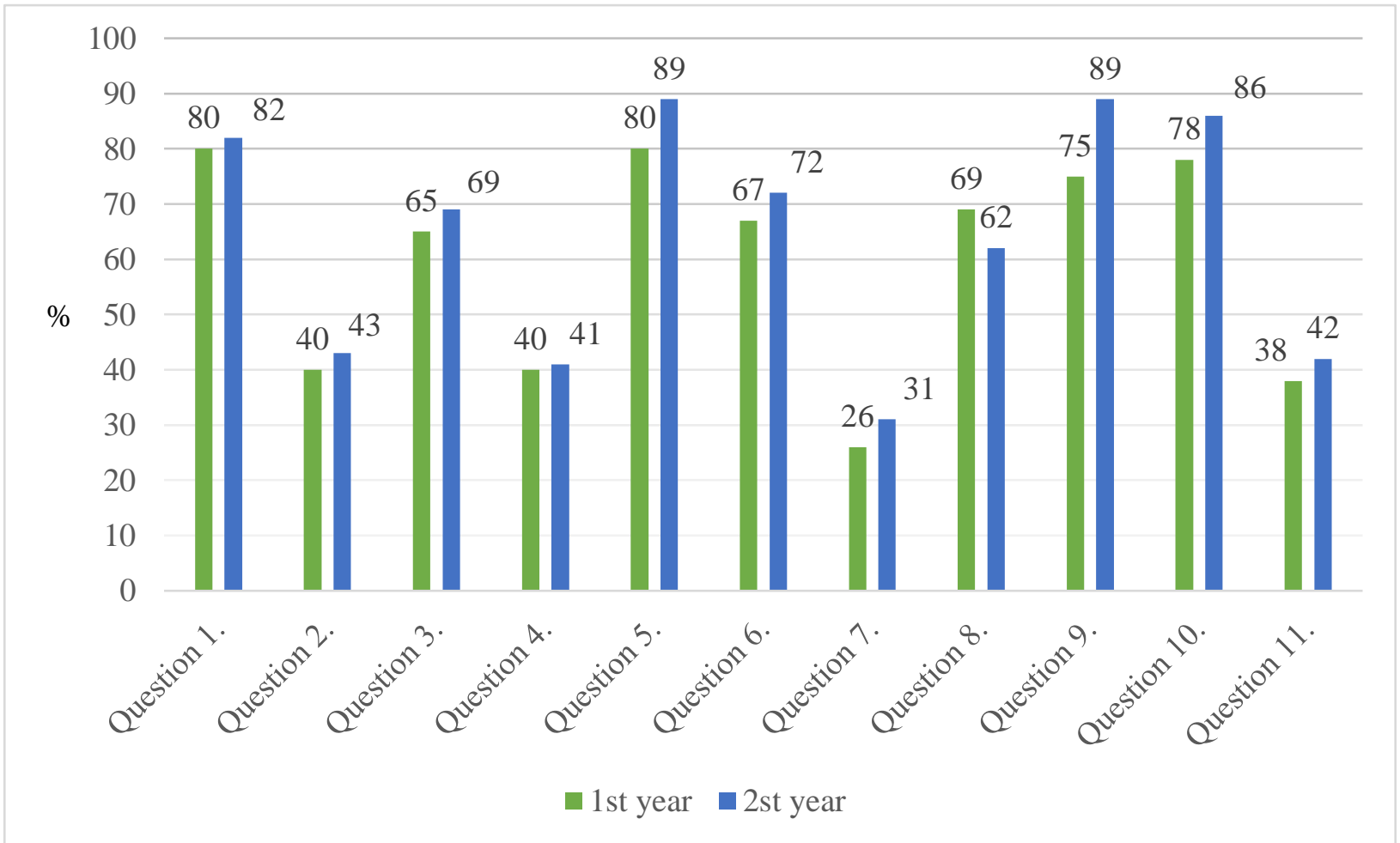

Figure 1. Comparison of results of the professional competence of $1^{\text {st }}$ year and $2^{\text {nd }}$ year students of the technical university.

Within the framework of the questionnaire, students conducted a self-assessment on the indicators of professional competence, as well as the formation of personal level (Figure 1). Students had the opportunity to assess the indicators of professional competence and personal growth on conditionally allocated four levels: 4 - clearly formed (90-100 \%); 3 - sufficiently formed (75-89\%); 2 - takes place $(60-74 \%) ; 1$ - formed to a minimum degree $(0-59 \%)$.

As a basis, we took professional competencies (code) and their description for software engineers (code decryption). Conventionally, we have identified 4 levels of their degree of manifestation in the educational process (we have mentioned them in the experiment). If the student's response contained keywords or similar ones from the description of professional competencies, then we rated it as it is expressed (level 4), if it was absent (level 0), if it is weakly expressed - level 2, if there is, but it is not clear (level 3). 


\section{Results and Discussion}

The study made it possible to draw the following results.

The results showed that in the first question the current level of knowledge and skills in the field of professional activity can be described as sufficiently formed, the majority of students $80 \%$ ( $1^{\text {st }}$ year), $82 \%\left(2^{\text {nd }}\right.$ year $)$ has an idea about the essence of their professional activity and it is very significant, the remaining respondents $20 \%$ ( $1^{\text {st }}$ year $), 18 \%$ ( $2^{\text {nd }}$ year) consider it important and necessary. The study demonstrates positive dynamics of development in terms of indicators.

In the second question, respondents were asked to assess their knowledge of the characteristics of professional skills in the structure of engineering culture. The following data were obtained: a quarter of students (40\%-1 $1^{\text {st }}$ year, $43 \%-2^{\text {nd }}$ year) believe that they are sure about it, $35 \%$ ( $1^{\text {st }}$ year), $36 \%$ $\left(2^{\text {nd }}\right.$ year) believe are not completely sure about it, the remaining $25 \%$ ( $1^{\text {st }}$ year $), 21 \%$ ( $2^{\text {nd }}$ year) of respondents find it difficult to answer. In the second year there is a positive increase, although not so large compared to the first year. It means that this indicator is formed to a minimum degree.

In the third question, the majority $\left(65 \%-1^{\text {st }}\right.$ year, $69 \%-2^{\text {nd }}$ year) of students noted the presence of scientific and technical skills of a competent professional activity, characterized by the awareness of engineering activities, $25 \%$ ( $1^{\text {st }}$ year $), 26 \%$ ( $2^{\text {nd }}$ year) I not completely sure about this, and the other $10 \%\left(1^{\text {st }}\right.$ year $)$ and $5 \%\left(2^{\text {nd }}\right.$ year $)$ difficult to answer. In the second year there is a trend of positive growth, although not as large as in the first year. It signifies that this indicator takes place.

In the fourth question, $40 \%$ ( $1^{\text {st }}$ year $), 41 \%\left(2^{\text {nd }}\right.$ year $)$ of the respondents indicated the presence of a potential communicative and analytical skills, $30 \%\left(1^{\text {st }}\right.$ year $), 32 \%\left(2^{\text {nd }}\right.$ year $)$ not completely sure about that; $25 \%$ ( $1^{\text {st }}$ year), $22 \% 2^{\text {nd }}$ year) takes place; $5 \%$ ( $1^{\text {st }}$ year $), 5 \%$ ( $2^{\text {nd }}$ year $)$ difficult to answer. A small increase in this indicator indicates the need for additional work in the field of scientific and theoretical activities. Bachelor's degree as a whole has an applied character. It means that this indicator is formed to a minimum degree.

In the fifth question, the majority of $80 \%$ (1 $1^{\text {st }}$ year $), 89 \%$ ( $2^{\text {nd }}$ year $)$ of respondents noted the presence of a professional culture and ethics, the manifestation of a value attitude, in particular, awareness of the measure of responsibility for their professional activities. It signifies that this indicator is sufficiently formed.

In the sixth question, the majority of $67 \%\left(1^{\text {st }}\right.$ year $), 72 \%\left(2^{\text {nd }}\right.$ year $)$ respondents noted the presence of their theoretical training. It signifies that this indicator takes place.

In the seventh question $26 \%$ ( $1^{\text {st }}$ year $), 31 \%$ ( $2^{\text {nd }}$ year) respondents noted the presence of their practical training. It means that this indicator is formed to a minimum degree. A relatively small increase in this indicator is the result of the accumulation of theoretical knowledge and the possibility of applying them in practice and is associated with the fact that practical training should be supported by the experience of real activity in the professional sphere, and the student has his accumulated practical experience accumulated within the walls of his native university is objectively small. Students' practical training is perceived by modern employers as a primary indicator of professional maturity of young personnel in any field of activity.

In the eighth question $69 \%$ ( $1^{\text {st }}$ year), $62 \%$ ( $2^{\text {nd }}$ year) respondents expressed their opinion about their discipline in order to prevent failure in operation, have the potential to educate themselves, environmental safety organization of work, compliance with industry requirements for product quality. It signifies that this indicator takes place. A relatively small decrease in growth in the second year can be attributed to the fact that the student has already settled in the student environment compared to $1^{\text {st }}$ year students.

In the ninth question, $75 \%$ ( $1^{\text {st }}$ year $), 89 \%$ ( $2^{\text {nd }}$ year $)$ of respondents noted their adaptation to professional working conditions. This is characterized by the fact that in general, the technical university lays a positive dynamic in the development of professional competence. It signifies that this indicator is sufficiently formed.

In the tenth question, $78 \%\left(1^{\text {st }}\right.$ year $), 86 \%$ ( $2^{\text {nd }}$ year) of respondents expressed their opinion about their quality of ownership and use of cloud technologies. Information skills are applied. As the study shows, this indicator was particularly developed in both freshmen and sophomores. In addition, the Federal state 
Autonomous educational institution of higher professional education "Peter the Great St. Petersburg Polytechnic University" is active using of electronic information resources to which students, starting with the first year immersed in the electronic learning environment of the polytechnic university on 2 course information skills continue to gain a foothold. It signifies that this indicator is sufficiently formed.

In the eleventh question, $38 \%$ ( $1^{\text {st }}$ year $), 42 \%$ ( $2^{\text {nd }}$ year) of students noted the presence of personal growth, which, in turn, is the most important indicator of the process of personal development. It means that this indicator is formed to a minimum degree.

Based on the analysis of the results of the study, it can be acknowledged that in general, four components of professional competence show positive dynamics, which indicates a positive impact of the educational process of a technical university on the formation of professional competence. However, there are four components of professional competence such as assess their knowledge of the characteristics of professional skills in the structure of engineering culture, the presence of a potential communicative and analytical skills, the presence of their practical training, the presence of personal growth, that show slight downward trend. At the same time, such components as the presence of their theoretical training; the presence of scientific and technical skills of a competent professional activity; expression of opinion about the production discipline in order to prevent failure, the potential for self-education and selfestablishment, compliance with environmental safety of the organization of working team, compliance with industry requirements for product quality take place. The conducted research has shown that the awareness of the majority of the students of self-assessment of the current state of future computer engineers' professional competence is high and it is a good start for the targeted and effective action in the future for the benefit of all humanity. It can be also seen that the tendency of slightly increasing figures takes place. Nevertheless, it cannot be stated that this tendency is statistically different between $1^{\text {st }}$ and $2^{\text {nd }}$ year student. The level "Clearly formed is" is missing. As already stated before, there is the gap between the demands of employers and the real competence of graduates. It is important to have a closer collaboration between university and businesses. That can foster the improvement the preparedness of the future engineer students for business, and also to make sure that, upon starting their labour years, students have acquired the skills the businesses expect from them. The key organiser in the facilitation of this collaboration is the university who promotes and organises these collaboration opportunities.

The practical significance of this study is determined by the fact that the provisions and conclusions contained in the work contribute to the understanding of how to approach the formation of professional competence of an engineer, focusing on the development of certain professional and personal qualities; the fact that the research materials can be used by teachers and researchers in the educational process of a technical university.

\section{Conclusions}

Summarizing the above, we can conclude that the fruitful period of studies in a technical university is a milestone for students in a conscious search for their professional identity, laying the foundations of professional activity, implying self-determination, self-actualization and self-restoration. It is necessary to focus on the fact that in the process of training in a technical university theoretical knowledge acquires personal significance, is assimilated and becomes relevant. It should be noted that the features of engineering work impose high demands on both professional and personal characteristics of the engineer. The technical university provides a positive dynamics in the development of professional competence, providing ample opportunities to encourage the development of professional and personal potential student, creating conditions for professional development, reflected in the successful implementation of professional functions, as well as contributing to excellence, by bringing the personal contribution of the engineer, which enriches the experience of the profession in the engineering field. There is a qualitative growth in the following indicators: projective and prognostic skills; organizational skills; information skills; analytical skills and efficiency of knowledge; and the greatest development is obtained during training for the Bachelor's degree. 


\section{Bibliography}

1. Almazova N., Baranova T., Khalyapina L. (2019). Development of students' polycultural and ethnocultural competences in the system of language education as a demand of globalizing world. In: Z. Anikina (Ed.), Conference Going Global through Social Sciences and Humanities: A Systems and ICT Perspective. GGSSH 2019. Advances in Intelligent Systems and Computing, 907, 145-156. doi: 10.1007/978-3-030-11473-2_17

2. Azmi A.N., Kamin Y., Noordin M.K. (2018). Competencies of Engineering Graduates: What are the Employer's Expectations? International Journal of Engineering and technology, 7(2.29), 519-523. doi: 10.14419/ijet.v7i2.29.13811

3. Briede B., Pēks L. (2014). A constructivist approach in teaching in higher education for getting methodological and reflection competences. In V. Dislere (Ed.), The Proceedings of the International Scientific Conference Rural Environment. Education. Personality (REEP), 7. Jelgava: LLU, 84-89. Retrieved from https://llufb.llu.lv/conference/REEP/2014/Latvia-UnivAgricult-REEP-2014proceedings-84-89.pdf

4. Drabik M., Gil A., Nowacka U. (2013). Virtual Laboratory in the Engineering Education. In V. Dislere (Ed.), The Proceedings of the International Scientific Conference Rural Environment. Education. Personality (REEP), 6. Jelgava: LLU, 316-323. Retrieved from https://llufb.llu.lv/conference/REEP/2013/Latvia-Univ-Agricult_REEP_2013_ISSN_2255808X-316-323.pdf

5. Ertug Z.K., Goksel E. (2019). Yeni mezun mühendislerin aldıkları lisans eğitimine ilişkin görüşleri ve mesleki yeterlilik algıları [The views of newly graduate engineers' regarding to the undergraduate education received and perceptions of professional competence]. Iktisat ve idari bilimler dergisi, 14(2), 347-364. doi: 10.17153/oguiibf.468739 (in Turkish)

6. Federalnij zakon ob obrazovanii $v$ rpsijskoi federacii N 273-Ф3 [The Federal Law about Education in the Russian Federation N 273-Ф3]. (2019). Moscow: Russian Federation. Retrieved from http://zakon-ob-obrazovanii.ru/ (in Russian)

7. Goft R.M., Terpenny J.P. (2012). Engineering Design Education - Core Competencies. Industrial and Manufacturing Systems Engineering Conference Proceedings and Posters, 11. doi: $10.2514 / 6.2012-1222$

8. Knutson C. (2015). The 7 Success Competences for your Engineering Career. Retrieved from https://www.engineering.com/JobArticles/ArticleID/9621/The-7-Success-Competencies-for-

Your-Engineering-Career.aspx

9. Lasauskiene J., Bagdonaviciute J. (2018). Building Intercultural Competence through Different International Study Programs at University. In V. Dislere (Ed.), The Proceedings of the International Scientific Conference Rural Environment. Education. Personality (REEP), 11. Jelgava: Latvia University of Life Sciences and Technologies, 208-214. doi: 10.22616/REEP.2018.026

10. McKinley M. (2014). The Top 5 Competences for Quality Engineers. Retrieved from https://www.morganmckinley.ie/article/top-5-competencies-quality-engineers

11. Odinokaya M., Krepkaia T., Karpovich I., Ivanova T. (2019a). Self-Regulation as a Basic Element of the Professional Culture of Engineers. Education Sciences, 9(3), 200. doi: 10.3390/educsci9030200

12. Odinokaya M., Krepkaia T., Sheredekina O., Bernavskaya M. (2019b). The Culture of Professional Self-Realization as a Fundamental Factor of Students' Internet Communication in the Modern Educational Environment of Higher Education. Education Sciences, 9(3), 187. doi: 10.3390/educsci9030187

13. Rubtsova A. (2019). Socio-linguistic innovations in education: Productive implementation of intercultural communication. In IOP Conference Series: Materials Science and Engineering, 497(1):012059. doi: 10.1088/1757-899X/497/1/012059

14. Sinkus T. (2019). The Implementation of Transformative Case Study Model for the Development of Professional English Language Competence in Business Administration Studies. In V. Dislere (Ed.), The Proceedings of the International Scientific Conference Rural Environment. Education. Personality (REEP), 12. Jelgava: Latvia University of Life Sciences and Technologies, 165-172. doi: 10.22616/REEP.2019.021 